\title{
Clinical outcomes and case volume effect of transanal total mesorectal excision for rectal cancer: a systematic review
}

\author{
C. L. Deijen ${ }^{1}$ A. Tsai ${ }^{2}$ T. W. A. Koedam ${ }^{1}$ - M. Veltcamp Helbach ${ }^{3}$. \\ C. Sietses ${ }^{3}$ A. M. Lacy ${ }^{4}$ H. J. Bonjer ${ }^{1}$ J. B. Tuynman ${ }^{1}$
}

Received: 11 August 2016/Accepted: 3 October 2016/Published online: 16 November 2016

(C) The Author(s) 2016. This article is published with open access at Springerlink.com

\begin{abstract}
Transanal total mesorectal excision (TaTME) has been developed to improve quality of TME for patients with mid and low rectal cancer. However, despite enthusiastic uptake and teaching facilities, concern exists for safe introduction. TaTME is a complex procedure and potentially a learning curve will hamper clinical outcome. With this systematic review, we aim to provide data regarding morbidity and safety of TaTME. A systematic literature search was performed in MEDLINE (PubMed), EMBASE (Ovid) and Cochrane Library. Case reports, cohort series and comparative series on TaTME for rectal cancer were included. To evaluate a potential effect of case volume, low-volume centres ( $n \leq 30$ total volume) were compared with high-volume centres ( $n>30$ total volume). Thirty-three studies were identified (three case reports, 25 case series, five comparative studies), including 794 patients. Conversion was performed in $3.0 \%$ of the procedures. The complication rate was 40.3 , and $11.5 \%$ were major complications. The quality of the mesorectum was "complete" in $87.6 \%$, and the circumferential resection margin (CRM) was involved in $4.7 \%$. In low- versus highvolume centres, the conversion rate was 4.3 versus $2.7 \%$, and major complication rates were 12.2 versus $10.5 \%$,
\end{abstract}

C. L. Deijen

c.deijen@vumc.nl

1 Department of Surgery, VU University Medical Centre, PO Box 7057, 1007 MB Amsterdam, The Netherlands

2 Department of Surgery and Cancer, Imperial College London, London, UK

3 Department of Surgery, Gelderse Vallei Hospital Ede, Ede, The Netherlands

4 Department of Surgery, Hospital Clinic de Barcelona, Barcelona, Spain respectively. TME quality was "complete" in 80.5 versus $89.7 \%$, and CRM involvement was 4.8 and $4.5 \%$ in lowversus high-volume centres, respectively. TaTME for mid and low rectal cancer is a promising technique; however, it is associated with considerable morbidity. Safe implementation of the TaTME should include proctoring and quality assurance preferably within a trial setting.

Keywords Rectal cancer - Total mesorectal excision . Morbidity · Transanal $\cdot$ Case volume

\section{Introduction}

Transanal total mesorectal excision (TaTME) has had tremendous attention since its introduction in 2010 by the group of Lacy [1]. The TaTME technique has been developed to improve the quality of the TME procedure for patients with mid and low rectal cancer. In TaTME, the low pelvic mesorectum is approached through the anus using a laparoscopic single-port platform. Potentially, TaTME facilitates the quality of dissection and decreases the need for definitive colostomies and conversions to open technique. Moreover, the TaTME technique aims to achieve higher rates of complete specimens, better visual determination of the distal margin and lower rates of involved circumferential resection margin (CRM) compared to abdominal TME. Especially in low rectal cancer surgery, relative higher rates of incomplete specimens and higher rates of CRM involvement have been reported compared to tumours located in the upper rectum [2-11]. Mid and low rectal cancer are associated with worse outcome when compared to high rectal cancer due to the difficult access of the lower pelvis. The innovative TaTME technique has the potential to improve these results. However, randomised 
clinical trials evaluating this new technique are lacking [12-14].

Despite the potential benefits, concern exists for uncontrolled widespread adaptation. TaTME is a complex procedure and a learning curve might influence initial clinical results. Since poor surgical quality in rectal cancer is associated with poor outcome, quality assurance of the new surgical technique seems plausible. Early adaptors of the technique have shown favourable results, but new serious complications have also been published [15-18]. Urethra injury or pelvic side wall injury with bleeding and nerve damage has not been documented for the conventional low anterior resection (LAR) [2-11]. In addition, increased bacterial load as is observed after TaTME might induce the occurrence of presacral abscesses [19]. Most importantly, data regarding oncological outcome after TaTME for mid and low rectal cancer are still scarce [12-18]. Although the aim is to perform resection with intact specimen, rectal wall perforations are observed which can potentially result in tumour spill $[1,15]$. Concern exists if luminal contamination with tumour cells of the pelvis results in more recurrences despite a negative resection margin and good quality specimen. In addition to oncological outcome, the long-term functional outcome of the procedure has to be awaited. Potentially, lower anastomosis results in worse functional outcome compared to abdominal laparoscopic TME.

With this systematic review, we aim to provide a comprehensive overview of the current data regarding safety of the TaTME procedure reporting on perioperative and oncological results with specific focus on adverse events and outcomes.

\section{Materials and methods}

\section{Search strategy}

This systematic review was conducted according to the Preferred Reporting Items for Systematic Reviews and MetaAnalysis (PRISMA) guidelines [20]. MEDLINE (PubMed), EMBASE (Ovid) and the Cochrane Library were searched systematically. The search period was from January 12005 until July 1 2016. The following search terms were used: (((excision*[tiab] OR resection*[tiab] OR TME[tiab] OR TaTME[tiab] OR TAMIS[tiab] OR NOTES[tiab] OR proctectom*[tiab]) AND (transanal*[tiab] OR trans-anal*[tiab])) OR ((excision*[ot] OR resection*[ot] OR TME[ot] OR TaTME[ot] OR TAMIS[ot] OR NOTES[ot] OR proctectom*[ot]) AND (transanal*[ot] OR trans-anal*[ot]))) AND (((("Neoplasms"[Mesh] OR neoplas*[tw] OR tumor*[tw] OR tumour*[tw] OR cancer*[tw] OR malignan*[tw] OR oncolog*[tw] OR carcinom*[tw] OR adenocarcinom*[tw]) AND ("Rectum"[Mesh] OR rectum[tiab] OR rectal[tiab] OR colorect*[tiab] OR mesorect*[tiab])) AND
("surgery"[Subheading] OR surgery[tiab] OR surgical[tiab] OR operati*[tiab])) OR ("Rectal Neoplasms/surgery" [Mesh:noexp])). References of the retrieved papers were screened to search for additional reports.

\section{Inclusion and exclusion criteria}

Published clinical studies on TaTME for rectal cancer reporting clinical and pathological outcomes were included. Case reports, cohort series and comparative series were eligible. Abstracts, reports with no peer-reviewed data and reports on robotic TaTME were excluded. No restriction was made based on included number of patients. Only articles in European languages were included. Two reviewers independently assessed all titles, abstracts and full texts for potential inclusion. When required, a third reviewer was consulted. Included articles based on full text were checked for overlapping data with other studies. Studies with potential overlapping patient populations were excluded for the overall analysis and subanalysis regarding volume.

\section{Endpoints and data extraction}

The primary endpoints of this study were short-term morbidity and specimen outcome. The following data were collected from included studies: first author, year of publication, number of patients, patient and tumour characteristics (gender, BMI, age, ASA classification, tumour distance, clinical TNM stage, neoadjuvant therapy), surgical details (operative time, type of anastomosis, use of diverting ileostomy, approach with synchronous abdominal and transanal resection, intraoperative complications, conversion rate), pathology outcomes (TME quality, involvement of CRM, involvement of distal resection margin, pathological $\mathrm{T}$ and $\mathrm{N}$ stage) and post-operative outcomes (hospital stay, post-operative complications, 30-day mortality rate and local and distant recurrence rates after follow-up of 12 months).

Heterogeneity in data on the height of tumour restricted data evaluation. Therefore, height was adjusted using international accepted definitions for anal verge (baseline $0 \mathrm{~cm})$, dentate line $(+1.9 \mathrm{~cm})$ and anorectal junction (+4 cm) [21-23]. Post-operative complications were reported as classified by Clavien-Dindo [24]. Minor complications were defined as complications needing non-invasive treatment (Clavien-Dindo classification I or II), and major complications were defined as complications needing invasive treatment (Clavien-Dindo $\geq$ III).

\section{Subanalysis low-volume centres versus high-volume centres}

To identify a possible difference in outcome depending on the volume in the TaTME technique, subanalysis of all 
variables was performed comparing low-volume centres ( $n \leq 30$ total volume) with high-volume centres $(n>30$ total volume) and excluding potential (partial) duplicates of cases in publications by centres that published multiple cohort series [25].

\section{Statistical analysis}

For all participating patients from the different included studies, data for several variables were pooled in a way as if the patients participated in one study. The mean of the variable of interest of each included study was multiplied with the number of participants in that study, and subsequently, all thus obtained products were added up and divided by the total number of participants in all included studies to obtain a pooled mean. For percentages of dichotomous variables of the different studies, a comparable method was applied. Because of variation in the studies regarding reporting an overall mean or median for the specified endpoint, the mean percentages and weighted means are based on either mean or median of the reporting studies. Furthermore, ranges are used to show the minimum and maximum of the reported means or medians in the different studies. For comparing numeric variables of lowand high-volume centres, an independent $T$ test was used. Review Manager version 5.3.5 (2014) was used to calculate the risk difference of dichotomous outcomes of the comparative studies and to make forest plots. To account for clinical heterogeneity, the random effects model based on DerSimonian and Laird's method were used. A $p$ value $<0.05$ was considered statistically significant.

\section{Quality assessment: MINORS instrument}

Quality assessment of the included articles was performed using the MINORS instrument, an index for the assessment of non-randomised studies [26]. A total of eight items are scored for non-comparative studies and 12 for comparative studies. The items are scored 0 (not reported), 1 (reported but inadequate) or 2 (reported and adequate). The global ideal score is 16 for non-comparative studies and 24 for comparative studies.

\section{Results}

\section{Included studies}

The literature search identified a total of 3489 articles (EMBASE $n=2132$, PubMed $n=1314$ and Cochrane Library $n=43$ ). A total of 1581 duplicates were removed, and 1743 articles were excluded after screening title and reading abstract (performed by both $\mathrm{CD}$ and $\mathrm{AT}$ ), leaving

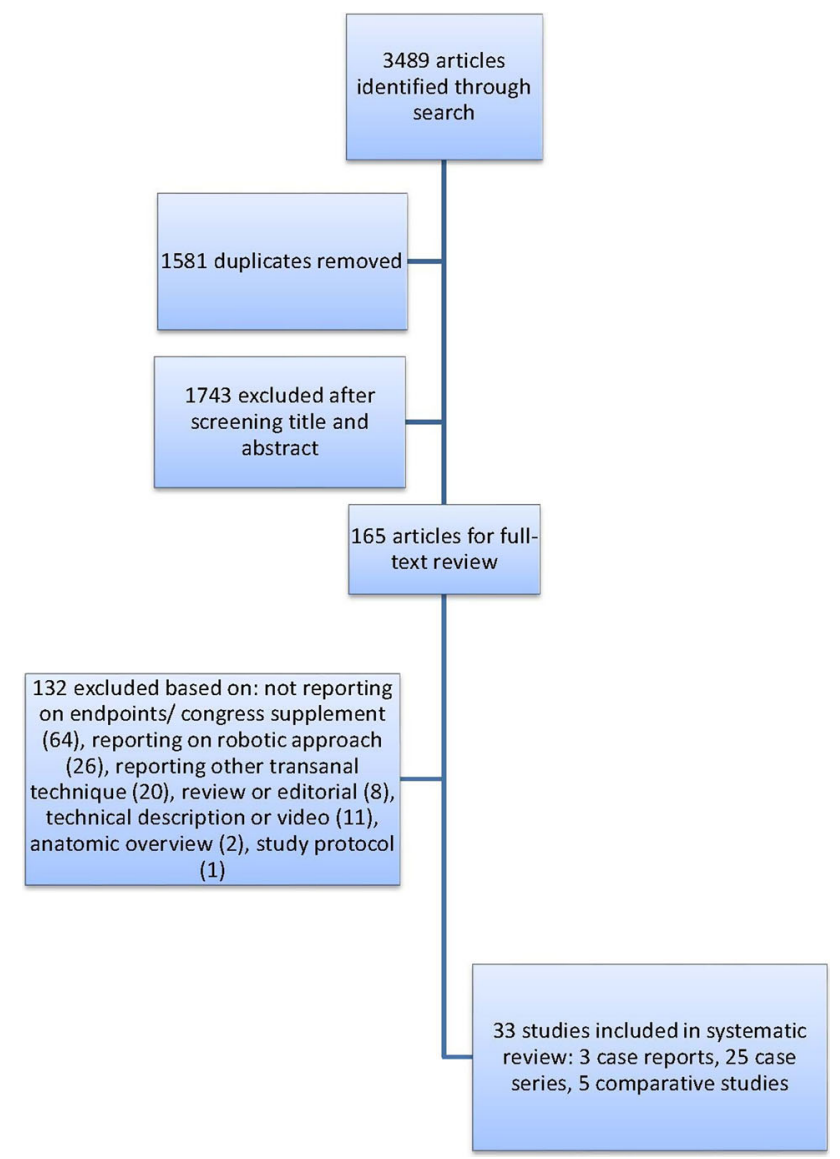

Fig. 1 Flow chart of selection process

165 articles for full-text review. Finally, 33 articles fulfilled all the inclusion criteria and met no exclusion criteria and were included for analyses [1, 15-18, 27-54]. These 33 articles comprised 3 case reports, 25 case series and 5 comparative studies (Fig. 1). The mean MINORS index of the non-comparative studies was 13 (range 8-15) and of the comparative studies 20 (range 20-21), indicating fair overall quality of the included articles. To correct for overlapping patient populations, 9 of these studies were not included in the overall analysis (Table 1).

\section{Patient and tumour characteristics}

In total, 794 patients were included, ranging from 1 patient to 140 patients per study. The tumour distance was measured from the anal verge in 24 studies, in 6 from the anorectal junction and in 3 from the dentate line. With correction for overlapping studies, in total 661 patients were included [444 males (67\%) and 217 females (33\%)] The calculated distance from the anal verge ranged from $2.0 \mathrm{~cm}$ to $8.4 \mathrm{~cm}$ with a weighted mean of $6.3 \mathrm{~cm}$. Other baseline and tumour characteristics are shown in Table 2. 
Table 1 Details of included studies

\begin{tabular}{|c|c|c|c|c|c|c|c|c|c|}
\hline \multirow{2}{*}{$\begin{array}{l}\text { Author } \\
\text { Sylla }^{\mathrm{a}}\end{array}$} & \multicolumn{2}{|c|}{$\begin{array}{l}\text { Year of } \\
\text { publication }\end{array}$} & \multirow{2}{*}{$\frac{N}{1}$} & Gender M & Gender F & \multirow{2}{*}{$\begin{array}{l}\begin{array}{l}\text { BMI } \\
\left(\mathrm{kg} / \mathrm{m}^{2}\right)\end{array} \\
20\end{array}$} & \multirow{2}{*}{$\begin{array}{l}\begin{array}{l}\text { Age } \\
\text { (year) }\end{array} \\
76\end{array}$} & $\begin{array}{l}\text { ASA score } \\
\text { (mean) }\end{array}$ & \multirow{2}{*}{$\begin{array}{l}\begin{array}{l}\text { Tumour distance } \\
(\mathrm{cm})^{\mathrm{b}}\end{array} \\
8\end{array}$} \\
\hline & 2010 & & & 0 & 1 & & & NR & \\
\hline Dumont & 2012 & & 4 & 4 & 0 & 23.4 & 66.8 & NR & 5.3 \\
\hline Zorron $^{\mathrm{a}}$ & 2012 & & 2 & 1 & 1 & NR & 65 & 1 & 7 \\
\hline Lacy $^{\mathrm{a}}$ & 2013 & & 3 & 1 & 2 & 21.7 & 73 & NR & 9.7 \\
\hline Lacy $^{\mathrm{a}}$ & 2013 & & 20 & 11 & 9 & 25.3 & 65 & 2 & 6.5 \\
\hline Sylla & 2013 & & 5 & 3 & 2 & 25.7 & 48.6 & NR & 5.7 \\
\hline Velthuis $^{\mathrm{a}}$ & 2013 & & 5 & 2 & 3 & NR & 69.4 & NR & 6 \\
\hline Rouanet & 2013 & & 30 & 30 & 0 & 26 & 65 & NR & 5 \\
\hline Zhang & 2013 & & 1 & 0 & 1 & 20 & 48 & NR & 7 \\
\hline Fernandez-Hevia $^{a}$ & 2014 & & 37 & 24 & 13 & 23.7 & 64.5 & 2 & 5.8 \\
\hline Velthuis $^{\mathrm{a}}$ & 2014 & & 25 & 18 & 7 & 25 & 64 & NR & 8 \\
\hline Atallah $^{\mathrm{a}}$ & 2014 & & 20 & 14 & 6 & 24 & 57 & 2 & 5 \\
\hline Chouillard & 2014 & & 16 & 6 & 10 & 27.9 & 57.7 & 2 & 8.4 \\
\hline Meng & 2014 & & 3 & 2 & 1 & NR & 80 & NR & 6.2 \\
\hline Zorron & 2014 & & 9 & 5 & 4 & NR & 62.6 & 1 & 7.56 \\
\hline Veltcamp Helbach & 2015 & & 80 & 48 & 32 & 27.5 & 66.5 & NR & 7.2 \\
\hline Tuech & 2015 & & 56 & 41 & 15 & 27 & 65 & 2 & 4 \\
\hline Muratore & 2015 & & 26 & 16 & 10 & 26.2 & 65.8 & NR & 4.4 \\
\hline Elmore & 2015 & & 6 & 2 & 4 & 25 & 61.3 & 2 & 5.5 \\
\hline Knol & 2015 & & 10 & 8 & 2 & 26.5 & 60.5 & NR & 6.89 \\
\hline Serra-Aracil & 2015 & & 32 & 24 & 8 & 25 & 68 & 2 & 8 \\
\hline Lacy & 2015 & & 140 & 89 & 51 & 25.2 & 65.5 & 2 & 7.6 \\
\hline Perdawood & 2015 & & 25 & 19 & 6 & 28 & 70 & 2 & 8 \\
\hline McLemore & 2015 & & 1 & 1 & 0 & 32 & 66 & NR & 2 \\
\hline Buchs $^{\mathrm{a}}$ & 2015 & & 20 & 14 & 6 & 27.1 & 59.3 & 2 & 6 \\
\hline Chen & 2015 & & 50 & 38 & 12 & 24.2 & 57.3 & 2 & 5.8 \\
\hline Prochazka & 2015 & & 17 & 11 & 6 & 28 & 68 & 3 & 6.0 \\
\hline Rink & 2015 & & 24 & 18 & 6 & 25 & 57 & 2 & 5 \\
\hline Burke & 2016 & & 50 & 30 & 20 & 26 & 56.5 & 2 & 4.4 \\
\hline Rasulov & 2016 & & 22 & 11 & 11 & 26 & 56 & NR & 6.5 \\
\hline Marks & 2016 & & 4 & 1 & 3 & 26 & 56 & NR & 5.1 \\
\hline Foo & 2016 & & 10 & 5 & 5 & 23.4 & 62.2 & 2 & 5.1 \\
\hline Buchs & 2016 & & 40 & 32 & 8 & 27.4 & 64.4 & 2 & 7 \\
\hline Author & $\begin{array}{l}\text { Year } \\
\text { publication }\end{array}$ & $N$ & $\begin{array}{l}\text { Conversion } \\
(\%)\end{array}$ & $\begin{array}{l}\text { TME quality } \\
(\%) \text { complete }^{\mathrm{e}}\end{array}$ & $\begin{array}{l}\text { Positive } \\
\text { resectio }\end{array}$ & $\begin{array}{l}\text { tal } \\
\operatorname{argin}(\%)\end{array}$ & $\begin{array}{l}\text { CRM } \\
\text { involvemer }\end{array}$ & pT3+ (\%) & $\begin{array}{l}\text { Harvested lymph } \\
\text { nodes }(\mathrm{N})\end{array}$ \\
\hline Sylla $^{a}$ & 2010 & 1 & 0 & 100 & 0 & & 0 & 0 & 23 \\
\hline Dumont & 2012 & 4 & 0 & $\mathrm{c}$ & 0 & & 0 & NR & 16 \\
\hline Zorron $^{\mathrm{a}}$ & 2012 & 2 & 0 & $\mathrm{c}$ & 0 & & 0 & 100 & 11.5 \\
\hline Lacy $^{\mathrm{a}}$ & 2013 & 3 & 0 & $\mathrm{c}$ & 0 & & 0 & 66.7 & NR \\
\hline Lacy $^{\mathrm{a}}$ & 2013 & 20 & 0 & $\mathrm{c}$ & 0 & & 0 & NR & 15.9 \\
\hline Sylla & 2013 & 5 & 0 & 100 & 0 & & 0 & 0 & 33 \\
\hline Velthuis $^{\mathrm{a}}$ & 2013 & 5 & NR & 100 & 0 & & 0 & 40 & 12 \\
\hline Rouanet & 2013 & 30 & 6.7 & 100 & 0 & & 0 & 100 & 12 \\
\hline Zhang & 2013 & 1 & 0 & 100 & 0 & & 13.3 & 70 & 13 \\
\hline Fernandez-Hevia $^{a}$ & 2014 & 37 & 0 & 91.9 & NR & & 0 & 62.2 & 14.3 \\
\hline Velthuis $^{\mathrm{a}}$ & 2014 & 25 & NR & 96 & NR & & 4 & NR & 14 \\
\hline Atallah $^{\mathrm{a}}$ & 2014 & 20 & NR & 55 & 5 & & 5 & 55 & 22.5 \\
\hline
\end{tabular}


Table 1 continued

\begin{tabular}{|c|c|c|c|c|c|c|c|c|c|}
\hline Author & $\begin{array}{l}\text { Year } \\
\text { publication }\end{array}$ & $N$ & $\begin{array}{l}\text { Conversion } \\
(\%)\end{array}$ & $\begin{array}{l}\text { TME quality } \\
(\%) \text { complete }^{\mathrm{e}}\end{array}$ & \multicolumn{2}{|c|}{$\begin{array}{l}\text { Positive distal } \\
\text { resection margin }(\%)\end{array}$} & $\begin{array}{l}\text { CRM } \\
\text { involvement (\%) }\end{array}$ & $\mathrm{pT} 3+(\%)$ & $\begin{array}{l}\text { Harvested lymph } \\
\text { nodes }(\mathrm{N})\end{array}$ \\
\hline Chouillard & 2014 & 16 & 6.3 & NR & \multicolumn{2}{|l|}{0} & 0 & 50.1 & 21 \\
\hline Meng & 2014 & 3 & 0 & \multirow{2}{*}{$\begin{array}{l}\text { NR } \\
\mathrm{b}\end{array}$} & \multicolumn{2}{|l|}{0} & 0 & 66.7 & NR \\
\hline Zorron & 2014 & 9 & 22 & & \multicolumn{2}{|l|}{0} & 11 & 66.7 & 13 \\
\hline $\begin{array}{l}\text { Veltcamp } \\
\text { Helbach }\end{array}$ & 2015 & 80 & 5 & 88.8 & \multicolumn{2}{|l|}{0} & 2.5 & 52.5 & 14 \\
\hline Tuech & 2015 & 56 & 5.4 & 83.9 & 0 & & 5.4 & 39.3 & 12 \\
\hline Muratore & 2015 & 26 & 0 & 88.5 & 0 & & 0 & 30.8 & 8 \\
\hline Elmore & 2015 & 6 & 0 & 100 & 0 & & 0 & 50 & 32 \\
\hline Knol & 2015 & 10 & 0 & 90 & 0 & & 0 & 40 & 10.5 \\
\hline Serra-Aracil & 2015 & 32 & 0 & 93.8 & 0 & & 0 & NR & 15 \\
\hline Lacy & 2015 & 140 & 0 & 97.1 & 0 & & 6.4 & NR & 14.7 \\
\hline Perdawood & 2015 & 25 & 0 & 80 & NR & & 4 & 68 & 21 \\
\hline McLemore & 2015 & 1 & 0 & 100 & NR & & NR & 0 & 13 \\
\hline Buchs $^{\mathrm{a}}$ & 2015 & 20 & 15 & 80 & 0 & & 5.9 & 25 & 23.3 \\
\hline Chen & 2015 & 50 & 2 & NR & NR & & 4 & NR & 16.7 \\
\hline Prochazka & 2015 & 17 & 0 & 47.1 & 0 & & 11.8 & 35.3 & 10 \\
\hline Rink & 2015 & 24 & NR & 91.67 & 0 & & 8.3 & 33.3 & 14 \\
\hline Burke & 2016 & 50 & 2.2 & 72 & 2 & & 4.0 & 50 & 18 \\
\hline Rasulov & 2016 & 22 & 4 & 68 & NR & & 5.0 & 23 & 17 \\
\hline Marks & 2016 & 4 & 0 & 100 & 0 & & 0.0 & 25 & 6 \\
\hline Foo & 2016 & 10 & 10 & 60 & 0 & & 0.0 & NR & 15.6 \\
\hline Buchs & 2016 & 40 & 7.5 & 92.5 & 0 & & 5.0 & 32.5 & 20 \\
\hline Author & Year & & $N$ & Hospital stay & (days) & Post-oper & ative complication & $(\%)$ & 30-Day \\
\hline & & & & & & Minor $^{f}$ & Majo & & \\
\hline Sylla $^{\mathrm{a}}$ & 2010 & & 1 & 4 & & 0 & 0 & & 0 \\
\hline Dumont & 2012 & & 4 & 13 & & 0 & 25 & & 0 \\
\hline Zorron $^{\mathrm{a}}$ & 2012 & & 2 & 6 & & 50 & 0 & & 0 \\
\hline Lacy $^{\mathrm{a}}$ & 2013 & & 3 & 4.7 & & 33.3 & 0 & & 0 \\
\hline Lacy $^{\mathrm{a}}$ & 2013 & & 20 & 6.5 & & 20 & 0 & & 0 \\
\hline Sylla & 2013 & & 5 & 5.2 & & 60 & 0 & & 0 \\
\hline Velthuis $^{\mathrm{a}}$ & 2013 & & 5 & NR & & 40 & 20 & & NR \\
\hline Rouanet & 2013 & & 30 & 14 & & 33.3 & 13.3 & & 0 \\
\hline Zhang & 2013 & & 1 & NR & & 0 & 0 & & 0 \\
\hline Fernandez-Hevia $^{a}$ & 2014 & & 37 & 6.8 & & 24.3 & 8.1 & & 0 \\
\hline Velthuis $^{\mathrm{a}}$ & 2014 & & 25 & NR & & NR & NR & & NR \\
\hline Atallah $^{\mathrm{a}}$ & 2014 & & 20 & 4.5 & & 75 & 25 & & 0 \\
\hline Chouillard & 2014 & & 16 & NR & & 0 & 18.8 & & 0 \\
\hline Meng & 2014 & & 3 & 6.5 & & 0 & 0 & & NR \\
\hline Zorron & 2014 & & 9 & 7.6 & & 11.1 & 11.1 & & 0 \\
\hline Veltcamp Helbach & 2015 & & 80 & 8 & & 26.3 & 12.5 & & 1 \\
\hline Tuech & 2015 & & 56 & 10 & & 19.6 & 5.4 & & 0 \\
\hline Muratore & 2015 & & 26 & 7 & & 15.4 & 11.5 & & 3.8 \\
\hline Elmore & 2015 & & 6 & 10.3 & & 0 & 33.3 & & 0 \\
\hline Knol & 2015 & & 10 & 6 & & 20 & 0 & & 0 \\
\hline Serra-Aracil & 2015 & & 32 & 8 & & 18.8 & 25 & & 0 \\
\hline Lacy & 2015 & & 140 & 6 & & 36.4 & 10 & & 0 \\
\hline Perdawood & 2015 & & 25 & 5 & & 28 & 24 & & 0 \\
\hline
\end{tabular}


Table 1 continued

\begin{tabular}{|c|c|c|c|c|c|c|}
\hline \multirow[t]{2}{*}{ Author } & \multirow{2}{*}{$\begin{array}{l}\text { Year } \\
\text { publication }\end{array}$} & \multirow[t]{2}{*}{$N$} & \multirow[t]{2}{*}{ Hospital stay (days) } & \multicolumn{2}{|c|}{ Post-operative complications (\%) } & \multirow{2}{*}{$\begin{array}{l}\text { 30-Day } \\
\text { mortality (\%) }\end{array}$} \\
\hline & & & & Minor $^{\mathrm{f}}$ & Major $^{\mathrm{f}}$ & \\
\hline McLemore & 2015 & 1 & 7 & 100 & 100 & 0 \\
\hline Buchs $^{\mathrm{a}}$ & 2015 & 20 & 7 & 25 & 10 & 0 \\
\hline Chen & 2015 & 50 & 7.4 & 20 & 6 & 0 \\
\hline Prochazka & 2015 & 17 & 9 & 23.5 & 11.8 & 0 \\
\hline Rink & 2015 & 24 & NR & 12.5 & 12.5 & 0 \\
\hline Burke & 2016 & 50 & 4.5 & 28 & 18 & 0 \\
\hline Rasulov & 2016 & 22 & 8 & 27 & 0 & 0 \\
\hline Marks & 2016 & 4 & 5 & 25 & 0 & 0 \\
\hline Foo & 2016 & 10 & 6 & 20 & 0 & 0 \\
\hline Buchs & 2016 & 40 & 7.5 & 27.5 & 12.5 & 0 \\
\hline
\end{tabular}

$B M I$ body mass index, ASA American Society of Anesthesiologists, NR not reported, TME total mesorectal excision, CRM circumferential resection margin

${ }^{a}$ Potentially overlapping patient population

b Measured from anal verge

c $\%$ of total patients with anastomosis

d $\%$ of total patients

e Defined by Quirke

${ }^{\mathrm{f}}$ Minor was defined as Clavien-Dindo classification I or II, and major was defined as $\geq$ III

Table 2 Baseline and tumour characteristics

\begin{tabular}{lll}
\hline & Weighted mean & Range \\
\hline Gender (\%) & 67 & \\
$\quad$ Male & 33 & \\
Female & 26.1 & $20-32$ \\
BMI $\left(\mathrm{kg} / \mathrm{m}^{2}\right)$ & 63.4 & $48-80$ \\
Age (years) & 2 & $1-3$ \\
ASA score (mean) & 6.3 & $2-8.4$ \\
Tumour distance $(\mathrm{cm})^{\mathrm{a}}$ & 71.6 & $40-100$ \\
cT3-T4 (\%) & 72.5 & $28-100$ \\
Neoadjuvant therapy $(\%)$ &
\end{tabular}

$B M I$ body mass index, ASA American Society of Anesthesiologists

${ }^{a}$ Measured from anal verge

\section{Surgical details}

The operative time ranged from 166 to 369 min with a weighted mean of $243.9 \mathrm{~min}$. In nine of the 33 studies, two surgical teams performed the surgery in some or all of the cases: one for the laparoscopic abdominal approach and one for the transanal approach, working simultaneously. For studies reporting on TaTME with two teams, the weighted mean for the operative time was $209.8 \mathrm{~min}$ (range 166-369) compared to 264.5 min (range 204-360) with one operating team. Other surgical details are depicted in Table 3.

\section{Procedure related complications}

In 18 studies, no intra-operative complications were reported, in one study no major complications were not reported, and in two studies the number of intra-operative complications was not mentioned. Of the 12 studies that did report intra-operative complications, five patients experienced side wall damage and five patients urethral damage during surgery. In two patients, the urethral lesion was repaired with sutures during the procedure not resulting in any documented problems postoperatively. In one patient, the lesion was managed non-operatively and no long-term sequelae were documented. In the other patients with urethral injury, the repair and outcome were not described. In four of the patients with side wall damage, the lesions were small without major post-operative morbidity and in the other patient outcome was not reported. One study reported early intraperitoneal $\mathrm{CO}_{2}$ leakage hampering the procedure. In one case, extensive pneumatosis of the retroperitoneum and mesentery of the small bowel was observed which stopped the procedure but did not result in any post-operative morbidity. One patient experienced an air embolism with temporary oxygen desaturation. In ten 
Table 3 Surgical details and clinical outcomes

\begin{tabular}{|c|c|c|}
\hline & Weighted mean & Range \\
\hline Conversion $(\%)$ & 3.0 & $0-22$ \\
\hline \multicolumn{3}{|l|}{ Post-operative complications (\%) } \\
\hline Minor $^{\mathrm{a}}$ & 28.8 & $0-100$ \\
\hline Major $^{\mathrm{a}}$ & 11.5 & $0-100$ \\
\hline Operative time (min) & 243.9 & $166-369$ \\
\hline Coloanal handsewn anastomosis $(\%)^{\mathrm{b}}$ & 53.9 & $0-100$ \\
\hline Diverting ileostomy $(\%)^{\mathrm{c}}$ & 90.3 & $25-100$ \\
\hline Colostomy $(\%)^{\mathrm{c}}$ & 4.7 & $0-28$ \\
\hline Two-team approach (\%) & 37.5 & $0-100$ \\
\hline Hospital stay (days) & 8.4 & $4.5-14$ \\
\hline 30-Day mortality (\%) & 0.3 & $0-3.8$ \\
\hline
\end{tabular}

${ }^{a}$ Minor was defined as Clavien-Dindo classification I or II, and major was defined as $\geq$ III

b $\%$ of total patients with anastomosis

c $\%$ of total patients

patients, bleeding occurred: in five, the source was the pelvic side wall, in three the bleeding was located presacrally, in one patient the bleeding was the result of injury to the iliac vessels, and in another patient the bleeding was located at the left side of the mesorectum. Finally, in one patient intraoperative bladder injury occurred. The defect was closed laparoscopically and treated with a urinary catheter for one week.

\section{Pathology outcomes}

At histopathological examination, different descriptions were used to define the quality of the mesorectum hampering accurate comparison. In the studies using the definition based on Quirke's classification $(n=19)$, the weighted mean of the quality of the mesorectum was "complete" in $87.6 \%$ and "nearly complete" in $10.9 \%$. Positive distal resection margins were found in $0.2 \%$ of the patients. The rate of involvement of CRM was $4.7 \%$. In $45.2 \%$ of the patients, a pT3 or pT4 tumour was found at pathological examination (Table 4).

\section{Post-operative outcomes and complications}

The duration of hospital stay ranged from 4.5 to 14 days with a weighted mean of 8.4 days. Total complication rate was $40.3 \%$. Complications reported were: anastomotic leak (37), urinary retention and urinary dysfunction (26), ileus (32), obstruction and intestinal occlusion (15), presacral abscess and pelvic sepsis (18), increased ileostomy output (16), blood transfusion (11), anastomotic stricture (11), haemorrhage (6), bleeding (6), (organ cavity) surgical site infection (8), fever (6), intra-abdominal collection (5),
Table 4 Pathology outcomes and follow-up

\begin{tabular}{lll}
\hline & $\begin{array}{l}\text { Weighted } \\
\text { mean }\end{array}$ & Range \\
\hline TME quality $(\%)^{\mathrm{a}}$ & & \\
$\quad$ Complete & 87.6 & $47.1-100$ \\
Nearly complete & 10.9 & $0-52.9$ \\
Incomplete & 1.5 & $0-18$ \\
Distal resection margin involvement (\%) & 0.2 & $0-2$ \\
CRM involvement (\%) & 4.7 & $0-13.3$ \\
pT3-T4 (\%) & 45.2 & $0-100$ \\
Recurrence & & \\
Local (\%) & 4 & $0-16.7$ \\
Distant (\%) & 8.1 & $5.4-14$ \\
Follow-up (months) & 18.9 & $15.1-29$ \\
\hline
\end{tabular}

TME total mesorectal excision, CRM circumferential resection margin

${ }^{a}$ Defined by Quirke

${ }^{\mathrm{b}}$ Only $>12$ months

colitis after ileostomy closure (4), nosocomial infection (3), pneumonia (3), small bowel laceration (2), rectovaginal fistula (2), resection of ischaemic conduit (2), perianastomotic fluid collections (2), wound infection (2), acute renal failure (1), anastomotic fistula (1), ureteral stent placement (1), ischaemia of the proximal limb of the colon (1), anastomotic sinus (1), superficial necrosis of colostomy (1), early adhesions (1), internal herniation (1), large haematoma (1), cerebral infarction (1), peritonitis (1), pelvic haematoma (2), septic shock (1), inguinal lymphorrea (1), myocardial infarction (1), pulmonary embolism (1), pelvic collection (1), bilateral calf compartment syndrome (1), prolapsing ischaemic anal mucosa (1), perineal wound dehiscence after proctocolectomy (1), gastroparesis (1), necrosis of descending colon due to injury to marginal artery (1), transient paresthesia of both feet due to intraoperative positioning (1), ascites (1), acute post-operative pancreatitis (1), pseudomembranous colitis (1), necrosis of stoma (1) and enterostomy-related other (1). Post-operative complications defined as minor occurred in $29.5 \%$ (range 0-100\%) and major complications occurred in $11.3 \%$ (range $0-100 \%$ ). Thirty-day post-operative mortality occurred in two patients in two different studies, accounting for a weighted mean of $0.3 \%$. One patient suffered from anastomotic leak and died after re-operation due to septic complications. The other patient died three days after the operation as a result of myocardial infarction (Table 3).

\section{Long-term oncological outcomes}

None of the studies had 3-year complete follow-up to calculate 3-year disease-free survival. Five studies (including 302 patients) reported follow-up of more than 
12 months. Overall time of follow-up was 18.9 months. The local and distant recurrence rates were 4.0 and $8.1 \%$, respectively (Table 4). In one of these studies, five local recurrences occurred during the follow-up period of 21 months. Another study reported two local recurrences, as well as three lung metastases at median follow-up of 29 months. Further, ovarian metastases (1) and para-aortic lymph node metastases (1) were reported in another study after a mean follow-up of 23 months. Another study reported one patient with local recurrence, eight patients with systemic recurrences and two patients with local and systemic recurrence at a median follow-up of 15.1 months. Finally, one study reported two patients with local recurrences and seven patients who developed distant metastases at a median follow-up of 15.1 months.

\section{Comparative studies}

Five of the included studies evaluated laparoscopic TME versus TaTME in a case-matched study design. Subanalysis of these five studies showed that the weighted means of conversion were 5.4 versus $1.4 \%$ for laparoscopic TME and TaTME, respectively. The risk difference of conversion was -0.03 (95\% CI -0.08 to $0.03 ; p=0.33$ ). For post-operative complications, the weighted means were 34.0 versus $30.4 \%$, respectively, with a risk difference of -0.10 (95\% CI -0.27 to $0.06 ; p=0.22$ ). TME completeness was reported in $75.2 \%$ in the laparoscopic TME group and $82.8 \%$ in the TaTME group. The risk difference was $-0.01(95 \% \mathrm{CI}-0.07$ to $0.05 ; p=0.72)$. The weighted means of involvement of CRM were $7.6 \%$ in the laparoscopic TME group and $3.2 \%$ in the TaTME group with a risk difference of 0.07 (95\% CI -0.08 to 0.21 ; $p=0.37$ ) (Fig. 2).

\section{Outcome in low- versus high-volume centres}

The centres with a volume of $\leq 30$ patients were compared to the centres with a volume of $>30$ patients. Regarding surgical details, operative time was shorter in the highvolume centres ( 222.2 vs. $282.5 \mathrm{~min})$ and the procedure was more often performed with a two-team approach compared to low-volume centres (51.3 vs. $13.7 \%)$. Furthermore, the conversion rate was $4.3 \%$ in low-volume centres and $2.7 \%$ in high-volume centres. The TME quality was more often assessed as "complete" in high-volume centres ( 80.5 vs. $89.7 \%$ ), and CRM involvement was 4.8 and $4.5 \%$, respectively. Overall complications were comparable, but the major complication rate was lower in highvolume centres (12.2 vs. $10.5 \%)$ (Fig. 3). Long-term oncological data revealed a local recurrence rate of 8.9 versus $2.8 \%$ and distant recurrence rate of 7.7 versus $8.1 \%$ for the low- and high-volume centres, respectively, although the number of patients with long-term follow-up was limited (Table 5).

\section{Discussion}

This systematic review shows that the TaTME procedure is feasible and safe. The technique is associated with substantial morbidity with comparable rates as reported for laparoscopic abdominal TME. The outcome in terms of specimen quality and CRM rate seems adequate with 87.6 and $4.7 \%$, respectively. In addition, concern exists for the long-term local recurrence rate which is relatively high (4\%) despite a relative short follow-up period (18.9 months). Although numbers are insufficient to draw real conclusions yet and no significance was reached, subanalysis from case-matched control studies shows that TME has substantial lower conversion rate compared with the laparoscopic TME group. The weighted mean of the conversion rate in laparoscopic TME was 5.4 versus $1.4 \%$ in the TaTME group. Furthermore, specimen completeness was higher in the TaTME group (82.8\%) than in the laparoscopic TME group (75.2\%) and less patients had involvement of CRM in the TaTME group compared with the laparoscopic group (3.2 vs. $7.6 \%$ ).

The outcome parameters seem dependent on the volume since small volume centres report longer operation time and higher conversion rate. Furthermore, worse postoperative outcomes (higher colostomy rate, major morbidity, local recurrence rate and lower rate of complete specimens) are observed as compared to the high-volume cohorts.

The total morbidity of the TaTME procedure in this systematic review is comparable with the conventional laparoscopic TME as published in the large randomised trials which display $37-54 \%$ total complications [2-11]. Fernandez-Hévia et al. [35] showed a decrease in morbidity including decreased rate of anastomotic leakage compared to conventional TME surgery. This systematic review does not clearly show advantage of the TaTME over the published morbidity rate of LAR. One of the most frequent complications reported was anastomotic leakage which occurred in 37 out of 646 patients with anastomosis (5.7\%). The leakage rate compares favourably to reported leakage rates from laparoscopic TME at approximately $10 \%$ and this might be an advantage of the TaTME, although randomised data have to be awaited [5]. New possible hazardous complications for TaTME are reported, as urethral lesions and damage of the pelvic side wall which are a concern and need further attention in education. Furthermore, urinary disorders were reported in 26 patients $(3.3 \%)$ and pelvic abscesses/sepsis in 18 out of 794 patients (2.3\%). The reported incidence of presacral abscesses was 


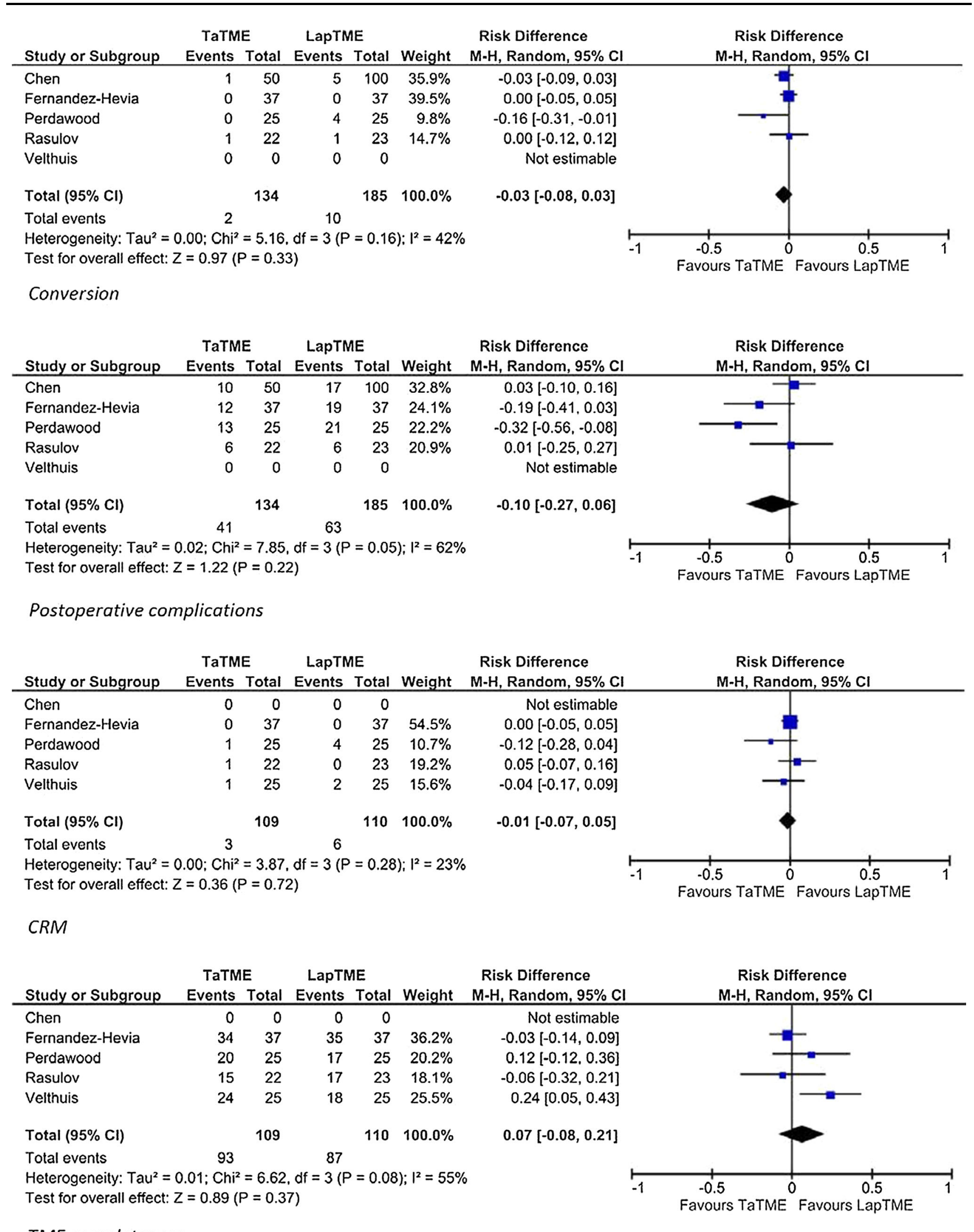

\section{TME completeness}

Fig. 2 Comparative studies 

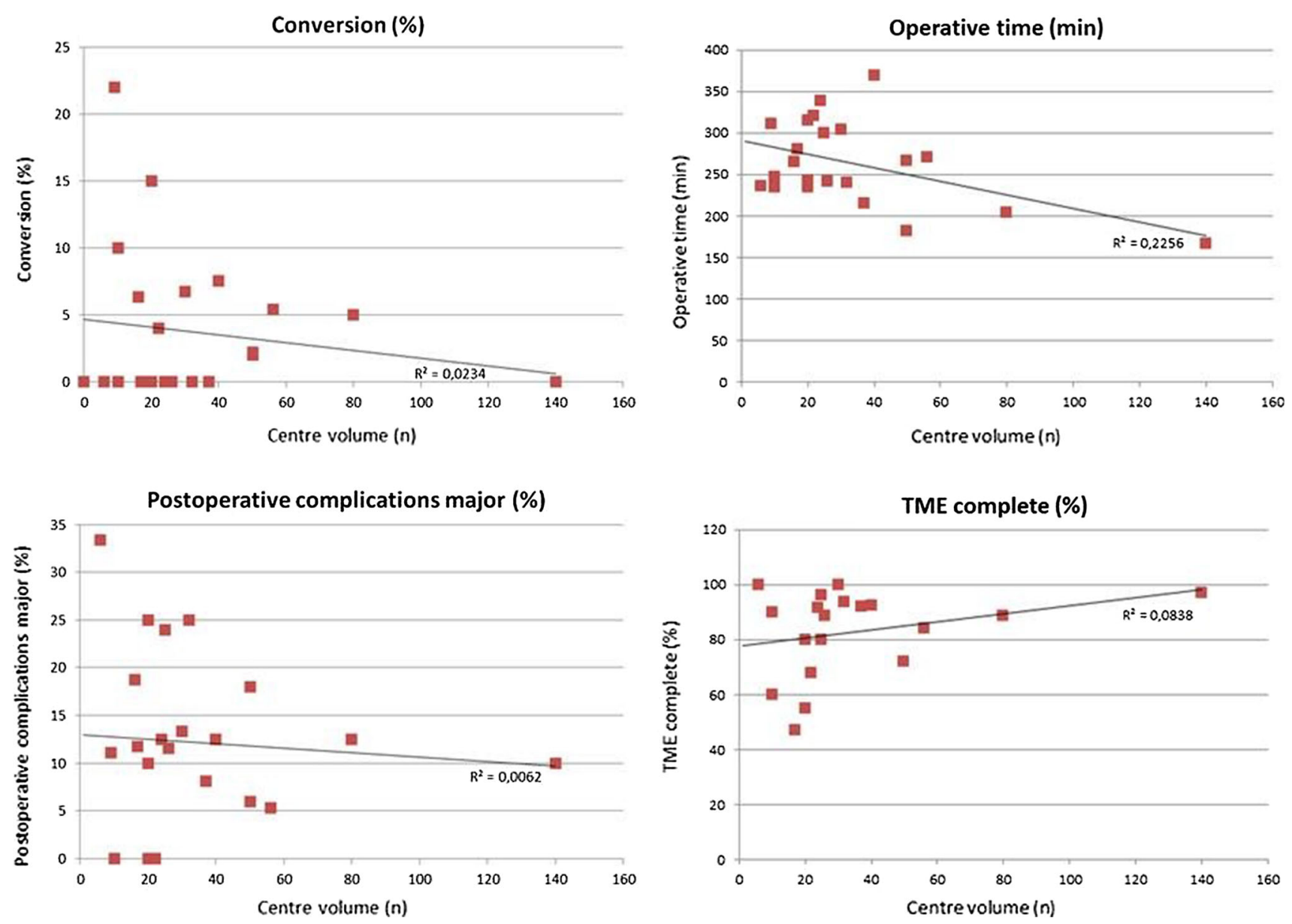

Fig. 3 Comparison of low-versus high-volume centres

not increased compared to the abdominal TME procedure. This is unexpected since it has been shown that increased bacterial load is present in the pelvis after TaTME [19]. The low rate of conversions compared to reported laparoscopic TME seems a major improvement and might be accounted as a benefit of TaTME. The reported colostomy rate is very low, but no conclusions can be drawn since considerable selection bias is present since cohort studies do not present intention-to-treat results.

Another potential advantage of the TaTME is improvement in oncological outcome. Surgical specimen quality defined by (1) mesorectal completeness, (2) CRM and (3) distal margins has been shown to be the most important prognostic factor predicting local recurrences [55]. Due to better visualisation in the deep pelvis, meticulous resection can be performed. Cohort and case series of TaTME for rectal cancer included in this systematic review have shown that $2.2 \%$ of the specimens were judged as incomplete. In $87 \%$ of the cases, the resected specimens were considered intact. In two of the largest randomised trials concerning laparoscopic rectal cancer surgery, the reported rates of complete specimens were 72 and $88 \%$
$[2,5]$. Another potential improvement in oncological outcome after TaTME is decrease in involvement of CRM. The average involved CRM rate after laparoscopic abdominal rectal resection in large randomised trials including TME is 6-8\% [2-10]. This systematic review shows an involved CRM rate of $4.3 \%$ after TaTME. CRM is a most significant prognostic factor for local recurrences and might relate to the expertise of the surgeon. Positive distal resection margins were found in $0.3 \%$ of the patients. These objective surgical quality measurements compare favourably to the published surgical laparoscopic rectal cancer studies, especially since the majority of the data are obtained from mid and low rectal cancer, whereas the large laparoscopic trials include low, mid and high rectal cancers [2-10]. It is debatable whether these data from cohort series can be compared to an audited clinical (randomised) trial. Nevertheless, TaTME potentially shows benefits over the laparoscopic TME regarding these oncological outcomes.

In the major trials investigating laparoscopic surgery for rectal cancer, the local recurrence rate for mid and low rectal cancer is approximately 5\% after three years 
Table 5 Comparison low- and high-volume centres

\begin{tabular}{|c|c|c|}
\hline & $\begin{array}{l}\text { Low-volume centres } \\
(n \leq 30) \\
\text { Weighted mean }\end{array}$ & $\begin{array}{l}\text { High-volume centres } \\
(n>30) \\
\text { Weighted mean }\end{array}$ \\
\hline Conversion $(\%)$ & 4.3 & 2.7 \\
\hline Post-operative complications $(\%)$ : minor $^{\mathrm{f}}$ & 21.9 & 25.2 \\
\hline Post-operative complications $(\%)$ : major ${ }^{\mathrm{f}}$ & 12.2 & 10.5 \\
\hline TME quality $(\%)$ : complete ${ }^{\mathrm{d}}$ & 80.5 & 89.7 \\
\hline TME quality (\%): nearly complete ${ }^{\mathrm{d}}$ & 15.1 & 9.0 \\
\hline TME quality (\%): incomplete ${ }^{\mathrm{d}}$ & 4.0 & 1.3 \\
\hline Distal resection margin involvement $(\%)$ & 0.4 & 0.3 \\
\hline CRM involvement (\%) & 4.8 & 4.5 \\
\hline pT3-T4 $(\%)$ & 44.3 & 45.1 \\
\hline Gender M (\%) & 65.8 & 67.4 \\
\hline Gender F $(\%)$ & 34.2 & 32.6 \\
\hline BMI $\left(\mathrm{kg} / \mathrm{m}^{2}\right)$ & 26.1 & 26.0 \\
\hline Age (years) & 62.3 & 63.8 \\
\hline ASA score (mean) & 2 & 2 \\
\hline Tumour distance $(\mathrm{cm})^{\mathrm{a}}$ & 6.0 & 6.5 \\
\hline cT3-T4 $(\%)$ & 71.3 & 69.3 \\
\hline Neoadjuvant therapy (\%) & 69.8 & 73.0 \\
\hline Operative time $(\mathrm{min})$ & 282.5 & 222.2 \\
\hline Coloanal handsewn anastomosis $(\%)^{\mathrm{b}}$ & 62.6 & 46.8 \\
\hline Diverting ileostomy $(\%)^{\mathrm{c}}$ & 89.8 & 88.8 \\
\hline Colostomy $(\%)^{\mathrm{c}}$ & 6.8 & 4.8 \\
\hline Two-team approach $(\%)$ & 13.7 & 51.3 \\
\hline Hospital stay (days) & 6.6 & 6.5 \\
\hline 30-Day mortality (\%) & 0.4 & 0.2 \\
\hline Recurrence: local $(\%)^{\mathrm{e}}$ & 8.9 & 2.8 \\
\hline Recurrence: distant $(\%)^{\mathrm{e}}$ & 7.7 & 8.1 \\
\hline Follow-up (months) ${ }^{\mathrm{e}}$ & 21.9 & 18.3 \\
\hline
\end{tabular}

TME total mesorectal excision, CRM circumferential resection margin, BMI body mass index, ASA American Society of Anesthesiologists

${ }^{a}$ Measured from anal verge

b $\%$ of total patients with anastomosis

c $\%$ of total patients

${ }^{\mathrm{d}}$ Defined by Quirke

e Only > 12 months

${ }^{\mathrm{f}}$ Minor was defined as Clavien-Dindo classification I or II, and major was defined as $\geq \mathrm{III}$
$[6-8,11]$. The local recurrence rate as shown in this systematic review is $4 \%$. However, this number is likely an underestimation due to the inadequate length of follow-up (18.9 months) and inadequate number of studies reporting follow-up. Interestingly, the involved CRM rate was similar to the local recurrence rate. Concern regarding intraluminal spread or other unknown factors exist, but it has to be noted that due to inadequate numbers and lack of longterm oncological follow-up preferably from randomised data no conclusions can be drawn.
This systematic review evidently shows a relationship between case volume and outcomes. Higher-volume centres have better outcome compared to small volume centres. Although statistical significance could not be obtained since lack of original data including standard deviations, a clear trend is visible. Operative time and conversion rate were lower, and the use of two simultaneous teams for the abdominal phase and the transanal phase during TaTME was performed more frequently in the high-volume centres compared to small volume centres. More interestingly, 
both quality of the resection and post-operative outcome were better in high-volume centres. However, an actual learning curve could not be extracted from the included studies, as a proficiency curve has yet to be determined and individual rates of series and outcomes were unavailable.

These data reflect the relative difficulty of the procedure requiring multiple skills including single-incision laparoscopic surgery (SILS) technique and two-team operating. As is known from colon surgery and oesophageal surgery, higher volume is associated with better outcomes [25]. For TaTME, this equation seems equal to the other difficult procedures. Although the quality of the data is non-randomised, this difference seems valid and calls for education, training and proctoring in order to have a safe introduction of the TaTME technique. A well-designed trial in which surgical quality assurance is an essential component should be ideal to evaluate the potential benefit of the TaTME technique. Before entering the trial, a surgeon should be trained and proctored and its surgical performance should be objectively monitored in order to exclude underperformance within the trial.

A major limitation of the available data is the lack of randomised evidence. Current cohort data are the result of the pioneers. The TaTME technique is technically demanding of both surgeon and team and requires a learning curve. Another limitation of this and previous systematic reviews is that the included studies are heterogeneous concerning clinical and tumour characteristics, surgical details and reporting of complications. Therefore, comparison of these studies and outcomes of this review should be carefully interpreted. Moreover, most of the studies include same patients in different reports. Abstracts, congress supplements and other unpublished data were not included with the aim to exclude major bias in contrast to previous published reviews. Furthermore, in the low- versus high-volume analysis, all (partial) duplicate publications were excluded. Nonetheless, most papers represent a small number of patients and high-quality studies are lacking. In the absence of published data concerning a learning curve or number of cases to achieve proficiency, we choose to use a cut-off point of 30 based on the traditional rectal surgery and agreement of the consensus group. We realize that this subanalysis is prone to bias. Furthermore, the majority of the studies exclude tumours with ingrowth in surrounding tissues. Especially, rectal cancer surgery in patients with T4 tumours is challenging and needs improvement, in specific regarding the quality of the resected specimen. Finally, adequate followup period of most studies is lacking and hampering any firm conclusions about long-term outcome.

Nevertheless, even at this early stage of implementation of the TaTME technique, it is important to provide a critical overview of the experience and outcomes of the procedure worldwide and especially to highlight the technical difficulty and possible hazardous aspects of TaTME. The TaTME consensus group has stated that at least 14 procedures a year have to be performed in order to assure optimal quality of the procedure [56]. To ensure save implementation and consistency in surgical quality, several TaTME expert centres across Europe and the USA provide training workshops and facilitate proctoring of the technique. Within the context of a future randomised controlled trial, quality assurance of this new technique seems of paramount importance.

In conclusion, TaTME is a potentially advantageous procedure for mid and low rectal cancer. Despite the current data available is mainly based on expert centres, considerable morbidity has been reported. In order to avoid unwanted negative outcome associated with widespread uncontrolled use of this novel technique, quality assurance and controlled safe implementation seem essential. TaTME has high potential; however, extensive evaluation in a welldesigned multicentre randomised trial is needed to come to unequivocal conclusions.

\section{Compliance with ethical standards}

Conflict of interest The authors declare that they have no conflict of interest.

Ethical approval This article does not contain any studies with human participants performed by any of the authors.

Informed consent For this type of study formal consent is not required.

Open Access This article is distributed under the terms of the Creative Commons Attribution 4.0 International License (http://crea tivecommons.org/licenses/by/4.0/), which permits unrestricted use, distribution, and reproduction in any medium, provided you give appropriate credit to the original author(s) and the source, provide a link to the Creative Commons license, and indicate if changes were made.

\section{References}

1. Sylla P, Rattner DW, Delgado S, Lacy AM (2010) NOTES transanal rectal cancer resection using transanal endoscopic microsurgery and laparoscopic assistance. Surg Endosc 24:1205-1210

2. Guillou PJ, Quirke P, Thorpe H, MRC CLASICC Trial Group et al (2005) Short-term endpoints of conventional versus laparoscopic-assisted surgery in patients with colorectal cancer (MRC CLASICC trial): multicentre, randomised controlled trial. Lancet 365:1718-1726

3. Kang SB, Park JW, Jeong SY et al (2010) Open versus laparoscopic surgery for mid or low rectal cancer after neoadjuvant chemoradiotherapy (COREAN trial): short-term outcomes of an open-label randomised controlled trial. Lancet Oncol 11:637-645

4. Sebag-Montefiore D, Stephens RJ, Steele R et al (2009) Preoperative radiotherapy versus selective postoperative chemoradiotherapy in patients with rectal cancer (MRC CR07 and NCIC-CTG C016): a multicentre, randomised trial. Lancet 373:811-820 
5. van der Pas MH, Haglind E, Cuesta MA, Colorectal cancer Laparoscopic or Open Resection II (COLOR II) Study Group et al (2013) Laparoscopic versus open surgery for rectal cancer (COLOR II): short-term outcomes of a randomised, phase 3 trial. Lancet Oncol 14:210-218

6. Jayne DG, Guillou PJ, Thorpe H, UK MRC CLASICC Trial Group et al (2007) Randomised trial of laparoscopic-assisted resection of colorectal carcinoma: 3-year results of the UK MRC CLASICC Trial Group. J Clin Oncol 25:3061-3068

7. Jeong SY, Park JW, Nam BH et al (2014) Open versus laparoscopic surgery for mid-rectal or low-rectal cancer after neoadjuvant chemoradiotherapy (COREAN trial): survival outcomes of an open-label, non-inferiority, randomised controlled trial. Lancet Oncol 15:767-774

8. Bonjer HJ, Deijen CL, Abis GA, COLOR II Study Group et al (2015) A randomised trial of laparoscopic versus open surgery for rectal cancer. N Engl J Med 372:1324-1332

9. Fleshman J, Branda M, Sargent D et al (2015) Effect of laparoscopic-assisted resection vs. open resection of stage II or III rectal cancer on pathologic outcomes: the ACOSOG Z6051 randomized clinical trial. JAMA 314:1346-1355

10. Stevenson AR, Solomon MJ, Lumley JW, ALaCaRT Investigators et al (2015) Effect of laparoscopic-assisted resection vs. open resection on pathological outcomes in rectal cancer: the ALaCaRT randomized clinical trial. JAMA 314:1356-1363

11. Peeters KC, Marijnen CA, Nagtegaal ID, Dutch Colorectal Cancer Group et al (2007) The TME trial after a median followup of 6 years: increased local control but no survival benefit in irradiated patients with resectable rectum carcinoma. Ann Surg 246:693-701

12. Emhoff IA, Lee GC, Sylla P (2014) Transanal colorectal resection using natural orifice translumenal endoscopic surgery (NOTES). Dig Endosc 1(26 Suppl):29-42

13. Araujo SE, Crawshaw B, Mendes CR, Delaney CP (2015) Transanal total mesorectal excision: a systematic review of the experimental and clinical evidence. Tech Coloproctol 19:69-82

14. Simillis C, Hompes R, Penna M, Rasheed S, Tekkis PP (2016) A systematic review of transanal total mesorectal excision: is this the future of rectal cancer surgery? Colorectal Dis 18:19-36

15. Veltcamp Helbach M, Deijen CL, Velthuis S, Bonjer HJ, Tuynman JB, Sietses C (2016) Transanal total mesorectal excision for rectal carcinoma: short-term outcomes and experience after 80 cases. Surg Endosc 30:464-470

16. Atallah S, Martin-Perez B, Albert M et al (2014) Transanal minimally invasive surgery for total mesorectal excision (TAMIS-TME): results and experience with the first 20 patients undergoing curative-intent rectal cancer surgery at a single institution. Tech Coloproctol 18:473-480

17. Tuech JJ, Karoui M, Lelong B et al (2015) A step toward NOTES total mesorectal excision for rectal cancer: endoscopic transanal proctectomy. Ann Surg 261:228-233

18. Lacy AM, Tasende MM, Delgado S et al (2015) Transanal total mesorectal excision for rectal cancer: outcomes after 140 patients. J Am Coll Surg 221:415-423

19. Velthuis S, Veltcamp Helbach M, Tuynman JB, Le TN, Bonjer HJ, Sietses C (2015) Intra-abdominal bacterial contamination in TAMIS total mesorectal excision for rectal carcinoma: a prospective study. Surg Endosc 29:3319-3323

20. Moher D, Shamseer L, Clarke M, PRISMA-P Group et al (2015) Preferred reporting items for systematic review and meta-analysis protocols (PRISMA-P) 2015 statement. Syst Rev 4:1

21. Wasserman MA, McGee MF, Helenowski IB, Halverson AL, Boller AM, Stryker SJ (2016) The anthropometric definition of the rectum is highly variable. Int J Colorectal Dis 31:189-195

22. Keller DS, Paspulati R, Kjellmo A et al (2014) MRI-defined height of rectal tumours. Br J Surg 101:127-132
23. Salerno G, Sinnatamby C, Branagan G, Daniels IR, Heald RJ, Moran BJ (2006) Defining the rectum: surgically, radiologically and anatomically. Colorectal Dis 3(8 Suppl):5-9

24. Dindo D, Demartines N, Clavien PA (2004) Classification of surgical complications: a new proposal with evaluation in a cohort of 6336 patients and results of a survey. Ann Surg 240:205-213

25. Mackenzie H, Markar SR, Askari A, Ni M, Faiz O, Hanna GB (2016) National proficiency-gain curves for minimally invasive gastrointestinal cancer surgery. Br J Surg 103:88-96

26. Slim K, Nini E, Forestier D, Kwiatkowski F, Panis Y, Chipponi J (2003) Methodological index for NOn-randomises studies (MINORS): development and validation of a new instrument. ANZ J Surg 73:712-716

27. Dumont F, Goéré D, Honoré C, Elias D (2012) Transanal endoscopic total mesorectal excision combined with single-port laparoscopy. Dis Colon Rectum 55:996-1001

28. Zorron R, Phillips HN, Coelho D, Flach L, Lemos FB, Vassallo RC (2012) Perirectal NOTES access: "down-to-up" total mesorectal excision for rectal cancer. Surg Innov 19:11-19

29. Lacy AM, Adelsdorfer C, Delgado S, Sylla P, Rattner DW (2013) Minilaparoscopy-assisted transrectal low anterior resection (LAR): a preliminary study. Surg Endosc 27:339-346

30. de Lacy AM, Rattner DW, Adelsdorfer C et al (2013) Transanal natural orifice transluminal endoscopic surgery (NOTES) rectal resection: "down-to-up" total mesorectal excision (TME)short-term outcomes in the first 20 cases. Surg Endosc 27:3165-3172

31. Sylla P, Bordeianou LG, Berger D et al (2013) A pilot study of natural orifice transanal endoscopic total mesorectal excision with laparoscopic assistance for rectal cancer. Surg Endosc 27:3396-3405

32. Velthuis S, van den Boezem PB, van der Peet DL, Cuesta MA, Sietses C (2013) Feasibility study of transanal total mesorectal excision. Br J Surg 100:828-831

33. Rouanet P, Mourregot A, Azar CC et al (2013) Transanal endoscopic proctectomy: an innovative procedure for difficult resection of rectal tumours in men with narrow pelvis. Dis Colon Rectum 56:408-415

34. Zhang $\mathrm{H}$, Zhang YS, Jin XW, Li MZ, Fan JS, Yang ZH (2013) Transanal single-port laparoscopic total mesorectal excision in the treatment of rectal cancer. Tech Coloproctol $17: 117-123$

35. Fernández-Hevia M, Delgado S, Castells A et al (2015) Transanal total mesorectal excision in rectal cancer: short-term outcomes in comparison with laparoscopic surgery. Ann Surg 261:221-227

36. Velthuis S, Nieuwenhuis DH, Ruijter TE, Cuesta MA, Bonjer HJ, Sietses C (2014) Transanal versus traditional laparoscopic total mesorectal excision for rectal carcinoma. Surg Endosc 28:3494-3499

37. Chouillard E, Chahine E, Khoury G et al (2014) NOTES total mesorectal excision (TME) for patients with rectal neoplasia: a preliminary experience. Surg Endosc 28:3150-3157

38. Meng W, Lau K (2014) Synchronous laparoscopic low anterior and transanal endoscopic microsurgery total mesorectal resection. Minim Invasive Ther Allied Technol 23:70-73

39. Zorron R, Phillips HN, Wynn G, Neto MP, Coelho D, Vassallo RC (2014) "Down-to-Up" transanal NOTES total mesorectal excision for rectal cancer: preliminary series of 9 patients. J Minim Access Surg 10:144-150

40. Muratore A, Mellano A, Marsanic P, De Simone M (2015) Transanal total mesorectal excision (taTME) for cancer located in the lower rectum: short- and mid-term results. Eur J Surg Oncol 41:478-483

41. Elmore U, Fumagalli Romario U, Vignali A, Sosa MF, Angiolini MR, Rosati R (2015) Laparoscopic anterior resection with 
transanal total mesorectal excision for rectal cancer: preliminary experience and impact on postoperative bowel function. J Laparoendosc Adv Surg Tech A 25:364-369

42. Knol JJ, D’Hondt M, Souverijns G, Heald B, Vangertruyden G (2015) Transanal endoscopic total mesorectal excision: technical aspects of approaching the mesorectal plane from below-a preliminary report. Tech Coloproctol 19:221-229

43. Serra-Aracil X, Mora-López L, Casalots A, Pericay C, Guerrero R, Navarro-Soto S (2016) Hybrid NOTES: TEO for transanal total mesorectal excision: intracorporeal resection and anastomosis. Surg Endosc 30:346-354

44. Perdawood SK, Al Khefagie GA (2016) Transanal vs. laparoscopic total mesorectal excision for rectal cancer: initial experience from Denmark. Colorectal Dis 18:51-58

45. McLemore EC, Harnsberger CR, Broderick RC et al (2015) Transanal total mesorectal excision (taTME) for rectal cancer: a training pathway. Surg Endosc 30:4130-4135

46. Buchs NC, Nicholson GA, Yeung T et al (2016) Transanal rectal resection: an initial experience of 20 cases. Colorectal Dis $18: 45-50$

47. Chen CC, Lai YL, Jiang JK et al (2016) Transanal total mesorectal excision versus laparoscopic surgery for rectal cancer receiving neoadjuvant chemoradiation: a matched case-control study. Ann Surg Oncol 23:1169-1176

48. Procházka V, Kala Z, Škrovina M, Grolich T, Klos K (2015) Transanal total mesorectal excision for low rectal cancer-first results. Rozhl Chir 94:64-68

49. Rink AD, Kauff DW, Paschold M, Vestweber KH, Lang H, Kneist W (2016) Hybrid TAMIS total mesorectal excision: a new perspective in treatment of distal rectal cancer-technique and results. Chirurg 87:225-232

50. Foo DC, Choi HK, Wei R, Yip J, Law WL (2016) Transanal total mesorectal excision with single-incision laparoscopy for rectal cancer. JSLS 20:e2016.00007

51. Marks JH, Lopez-Acevedo N, Krishnan B, Johnson MN, Montenegro GA, Marks GJ (2016) True NOTES TME resection with splenic flexure release, high ligation of IMA, and side-to-end hand-sewn coloanal anastomosis. Surg Endosc 30:4626-4631

52. Rasulov AO, Mamedli ZZ, Gordeyev SS, Kozlov NA, Dzhumabaev HE (2016) Short-term outcomes after transanal and laparoscopic total mesorectal excision for rectal cancer. Tech Coloproctol 20:227-234

53. Burke JP, Martin-Perez B, Khan A et al (2016) Transanal total mesorectal excision for rectal cancer: early outcomes in 50 consecutive patients. Colorectal Dis 18:570-577

54. Buchs NC, Wynn G, Austin R et al (2016) A two centre experience of transanal total mesorectal excision. Colorectal Dis. doi:10.1111/codi.13394

55. Nagtegaal ID, Marijnen CA, Kranenbarg EK, van de Velde CJ, van Krieken JH, Pathology Review Committee, Cooperative Clinical Investigators (2002) Circumferential margin involvement is still an important predictor of local recurrence in rectal carcinoma: not one millimeter but two millimeters is the limit. Am J Surg Pathol 26:350-357

56. Penna M, Hompes R, Mackenzie H, Carter F, Francis NK (2016) First international training and assessment consensus workshop on transanal total mesorectal excision (taTME). Tech Coloproctol $20: 343-352$ 